\title{
Pulmonary myofibroblastic tumor - A forgotten lesion
}

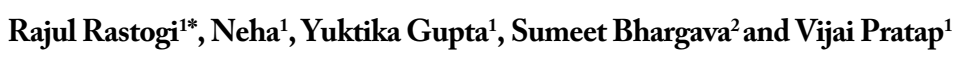 \\ ${ }^{1}$ Department of Radiodiagnosis, Teerthanker Mahaveer Medical College \& Research Center, Moradabad, Uttar Pradesh, India \\ ${ }^{2}$ MSY Medical College \& Hospital, Meerut, Uttar Pradesh, India
}

\begin{abstract}
Pulmonary myofibroblastic tumor is a rare benign lesion often termed as inflammatory pseudotumor. It is a slow-growing, true neoplasm comprising less than $1 \%$ of pulmonary tumors thus forming a differential diagnosis of pulmonary tumors and infections in childhood and young adults. Complete resection results in cure unlike in many malignant lesions. Hence, this article tries to bring out the classical radiological features of this rare pseudo-malignant lesion in a young female along with its differential features.
\end{abstract}

\section{Introduction}

Pulmonary myofibroblastic tumor, also known at inflammatory myofibroblastic tumor (IMT) is a rare benign lesion of lung that comprises less than one percent of all pulmonary tumors [1]. Although its nomenclature has the term inflammatory, but it is a true tumor [2]. IMT is commoner in children and young adults without sex predilection [2,3]. Patients symptomatology is usually nonspecific ranging from fever, cough, dyspnea, chest pain and hemoptysis with anorexia and weight loss being rare [2-4]. Often the lesion is detected incidentally on chest radiograph done for chronic cough [4-6]. Pathologically, the lesion shows clusters of spindle cells in a background of inflammatory cells viz. lymphocytes, plasma cells and eosinophils $[4,5]$. Immunohistochemical stains are usually positive for anaplastic lymphoma receptor tyrosine kinase (ALK1), smooth muscle actin and H-caldesmon with negative PS100 [4,5].

The tumor is usually solitary and can arise from variety of sites in human body including most commonly from lungs \& other parts of respiratory tract followed by esophagus \& gastrointestinal tract, urinary bladder, spleen \& lymph nodes, central nervous system, epididymis and soft tissues [4,5]. Multiple, isolated, case reports on variegated clinical presentation and radiological features have been reported in literature with very few review articles [7]. None of the article focusses primarily on radiological features which we have tried in this case report.

\section{Case report}

A thirty-year old female with history of chronic cough and mass lesion on chest radiograph came for contrast-enhanced computed tomography (CECT) of thorax. Rest of clinical history and laboratory investigations of the patient were unremarkable. Non contrast computed tomography images through upper thorax revealed a well-defined, heteroattenuating, ovoid mass epicentered in the apicoposterior segment of right upper lobe in medial and subpleural location showing multiple, irregular areas of calcification (Figure 1). Minimal to mild postcontrast enhancement was noted within the lesion on CECT thorax without evidence of any internal necrosis or air-bronchogram (Figure 2). There was slight pleural thickening adjacent to the lesion without evidence of any mediastinal or pleural invasion. No evidence of any obvious hilar or mediastinal adenopathy was noted. No evidence of any

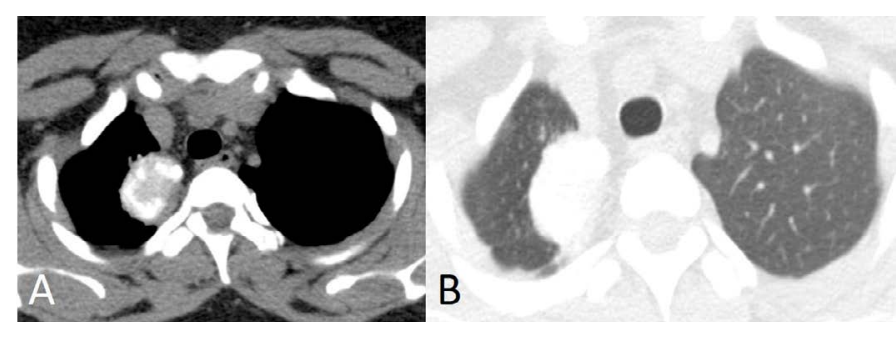

Figure 1. Noncontrast Transaxial CT image in mediastinal (A) \& lung (B) window settings shows IMT in right upper lobe with areas of dense calcification.

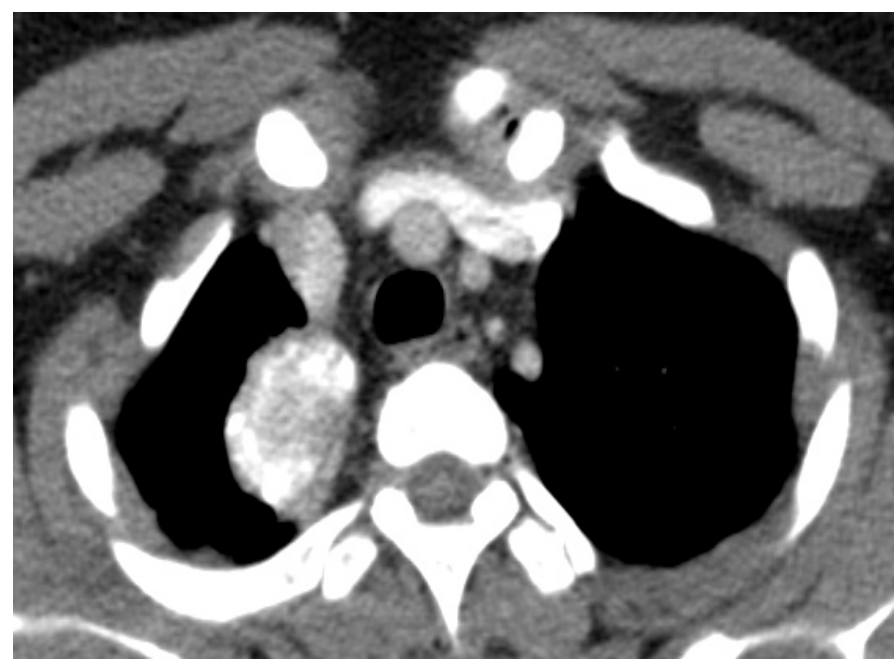

Figure 2. Contrast-enhanced Transaxial CT image in mediastinal window settings shows minimal to mild enhancement of IMT in right upper lobe with areas of dense calcification but without obvious necrosis or air-bronchogram

${ }^{*}$ Correspondence to: Rajul Rastogi, Department of Radiodiagnosis, Teerthanker Mahaveer Medical College \& Research Center, Moradabad, Uttar Pradesh, India, Email: eesharastogi@gmail.com

Key words: pulmonary, myofibroblastic, tumor, pseudotumor

Received: June 08, 2020; Accepted: June 16, 2020; Published: June 22, 2020 
other pulmonary nodule or mass / hepatic or adrenal lesion was noted. No evidence of any osseous involvement was noted. No evidence of any obvious pleural effusion or pneumothorax was noted.

Based on the clinicoradiological findings, the differential diagnosis of healing granuloma (tuberculoma) or benign pulmonary tumor with internal calcification (inflammatory myofibroblastic tumor) was given. Patient underwent CT-guided biopsy. Biopsy specimen revealed clusters of spindle cells (myofibroblastic type) in fibrous, myxoid and calcified stroma with an inflammatory component consisting predominantly of lymphocytes \& plasma cells with areas containing eosinophils. The final histopathological diagnosis was inflammatory myofibroblastic tumor.

\section{Discussion}

IMT was first described in lungs and had variegated nomenclature in past as inflammatory pseudotumor, plasma cell granuloma, histiocytoma and fibroxanthoma $[1,3,5]$. Cross-sectional imaging plays an important role in studying the tumor morphology, its extent and local extension. Though the radiological features of IMT in lungs are nonspecific but they are characteristic in children and young adults. It usually presents as a solitary pulmonary nodule or mass with smooth margins and internal calcification located peripherally commonly in lower lobe of lung $[1,2,5]$. Calcification is commoner in children with nearly one-third cases [8]. Our index case is unique as it revealed significant calcification within a mass lesion in young adult that too at an uncommon location of right upper lobe.

Multicentricity, cavitation within tumor and associated pleural effusion or atelectasis are rare. Positive octreoscan has been described in PET-CT in literature [9]. Despite its benign \& slow-growing nature, IMT is considered as a low-grade tumor by majority due to invasive nature, recurrence following incomplete resections and rare malignant transformation [5,10]. Association of IMT with IgG4 syndrome has been suggested in literature [10]. Complete resection is the gold standard treatment protocol for IMT as partial excision is frequently associated with recurrence $[1,4,9]$. Corticosteroids are used in children with hilar or mediastinal invasion or unresectable tumors $[5,9]$. Chemotherapy is reserved for multifocal or invasive or locally recurrent tumors [11]. Ten-year survival rate of $80 \%$ has been described in literature [12]. Differential diagnosis of IMT are multiple. IMT may mimic foreign body especially in children with lobar / lung atelectasis. Infectious disease especially tuberculosis \& aspergillosis in form of solitary granuloma may mimic IMT in areas of high incidence when associated with fever \& cough. IMT with fluid attenuating may mimic necrotizing pneumonia in kids but nonresponsive to antibiotic therapy is a clue to tumor rather than infection. Calcification when seen in an incidentally-detected, well-defined, space occupying pulmonary lesion without any other associated abnormality should raise the suspicion of IMT which can reveal slow-growth on follow-up. [13]

\section{Conclusion}

Pulmonary myofibroblastic tumor is a benign lung neoplasm with though nonspecific symptoms but characteristic radiological features helping its differentiation from more aggressive and graver pulmonary carcinoma in children \& young adults and its benign counterparts, especially granuloma.

\section{References}

1. Almadi A, Rami M, Khattala K, Chater L, Harmouch T, et al. (2011) Pseudotumeur inflammatoire pulmonaire chez un enfant. J Pediatr Puericulture 24: 69-71.

2. Zhang Y, Dong ZJ, Zhi XY, Liu L, HU M (2009) Inflammatory myofibroblastic tumor in lung with pulmonary osteoarthropathy. Chin Med J 122: 3094-3096. [Crossref]

3. Rachil H, Saad S, Amar BJ, Rouhou CS, Zarrouk M, et al. (2011) Pseudotumeur inflammatoire pulmonaire invasive. Revu Med Interne 32: e55-e58.

4. Joshi KP, Kaphle U, Steliga MA, Bartter T, Priyambada P, et al. (2017) Inflammatory Myofibroblastic Tumor of the Lung A Rare Primary Lung Cancer. Am J Respir Crit Care Med 196: 923-924. [Crossref]

5. Hammas N, Chbani L, Rami M, Boubbou M, Benmiloud S, et al. (2012) A rare tumor of the lung: inflammatory myofibroblastic tumor. Diagnostic Pathology 7: 83. [Crossref]

6. Panagiotopoulos N, Patrini D, Gvinianidze L, Woo WL, Borg E, et al. (2015) Inflammatory myofibroblastic tumour of the lung: a reactive lesion or a true neoplasm? J Thorac Dis 7: 908-911. [Crossref]

7. Camela F, Gallucci M, di Palmo E, Cazzato S, Lima M, et al. (2018) Pulmonary Inflammatory Myofibroblastic Tumor in Children: A Case Report and Brief Review of Literature. Front. Pediatr 6: 35. [Crossref]

8. Takayama Y, Yabuuchi H, Matsuo Y, Soeda H, Okafuji T, et al. (2008) Computed tomographic and magnetic resonance features of inflammatory myofibroblastic tumor of the lung in children. Radiat Med 26: 613-617. [Crossref]

9. Calabrese F, Zuin A, Brambilla E, Zucchetta P, Lunardi F, et al. (2010) Pulmonary inflammatory myofibroblastic tumour with unusual octreoscan uptake: two reports. Eur Respir J 35: 448-450. [Crossref]

10. Deshpande V, Zen Y, Chan JK, Yi EE, Sato Y, et al. (2012) Consensus statement on the pathology of IgG4-related disease. Mod Pathol 25: 1181-1192. [Crossref]

11. Pinillaa I, Herreroa Y, Torresa MI, Nistalb M, Pardoa M (2007) Tumor inflamatorio miofibroblatico pulmonary. Radiologa 49: 53-55.

12. Lawrence B, Perez-Atayde A, Hibbard MK, Rubin BP, Dal Cin P, et al. (2000) TPM3ALK and TPM4-ALK oncogenes in inflammatory myofibroblastic tumors. Am J Pathol 157: 377-384. [Crossref]

13. Weldon CB, Shamberger RC (2008) Pediatric pulmonary tumors: primary and metastatic. Semin Pediatr Surg 17: 17-29. [Crossref]

Copyright: (C2020 Rastogi R. This is an open-access article distributed under the terms of the Creative Commons Attribution License, which permits unrestricted use, distribution, and reproduction in any medium, provided the original author and source are credited. 